\title{
FACTORS THAT INFLUENCE TREATMENT DELAY FOR PATIENTS WITH BREAST
}

CANCER

María Padilla-Ruiz ${ }^{1,3}$, Irene Zarcos-Pedrinaci², ${ }^{2}$, Francisco Rivas-Ruiz ${ }^{1,3}$, Teresa Téllez ${ }^{3}$, Susana García-

Gutiérrez $^{3,4}$, Nerea González ${ }^{3,4}$, Amado Rivero $^{3,5}$, Pedro Serrano-Aguilar ${ }^{3,6}$, Xavier Castells ${ }^{3,7}$, José María Quintana $^{3,4}$, María Sala ${ }^{3,7}$, Maximino Redondo ${ }^{1,3, *}$ REDISSEC-CaMISS group.

1. Research Unit. Hospital Costa del Sol. Marbella. Spain.

2. Oncology Service. Hospital Costa del Sol. Marbella. Spain.

3. Health Services Network for Research into Chronic Diseases (REDISSEC). Madrid. Spain.

4. Research Unit, Galdakao-Usansolo Hospital Osakidetza. Galdakao. Bizkaia. Spain.

5. Canary Islands Foundation for Health Care Research (FUNCANIS). Tenerife. Spain.

6. Evaluation Unit of the Canary Islands Health Service (SESCS). Tenerife. Spain.

7. Department of Epidemiology and Evaluation, Hospital del Mar Medical Research Institute (IMIM), Autonomous University of Barcelona. Barcelona. Spain.

1. María Padilla-Ruiz: 0000-0002-2321-9211

2. Francisco Rivas-Ruiz: 0000-0002-8894-0501

3. Susana García: 0000-0002-8474-2479

4. Nerea González: 0000-0003-3928-3274

5. Amado Rivero: 0000-0002-5067-3196

6. Xavier Castells: 0000-0002-2528-0382

7. José María Quintana: 0000-0003-2170-7876

8. María Sala: 0000-0002-9955-8746

9. Maximino Redondo: 0000-0001-5559-4246

* Corresponding author: Agencia Sanitaria Costa del Sol. Unidad de Investigación. Autovía A-7. Km.187. Marbella 29603.Málaga, Spain.prmariac@gmail.com. Tel.: 951976620.

\section{Competing of interests}

The authors declare that they have no competing interests. 


\section{ABSTRACT}

\section{Introduction}

The diagnosis or treatment of breast cancer is sometimes delayed. A lengthy delay may have a negative psychological impact on patients. Our study aim is to evaluate the sociodemographic, clinical and pathological factors associated with delay in the provision of surgical treatment for localised breast cancer, in a prospective cohort of patients.

\section{Method}

This observational, prospective, multicentre study was conducted in ten hospitals belonging to the Spanish national public health system, located in four Autonomous Communities (regions). The study included 1236 patients, diagnosed through a screening programme or found to be symptomatic, between April 2013 and May 2015. The study variables analysed included each patient's personal history, care situation, tumour history and data on the surgical intervention, pathological anatomy, hospital admission and follow-up. Treatment delay was defined as more than 30 days elapsed between biopsy and surgery.

\section{Results}

Over half of the study population experienced surgical treatment delay. This delay was greater for patients with no formal education and among widows, persons not requiring assistance for usual activities, those experiencing anxiety or depression, those who had a high BMI or an above-average number of comorbidities, those who were symptomatic, who did not receive NMR spectroscopy, who presented a histology other than infiltrating ductal carcinoma or who had poorly-differentiated carcinomas.

\section{Conclusions}

Certain sociodemographic and clinical variables are associated with surgical treatment delay. This study identifies factors that influence surgical delays, highlighting the importance of preventing these factors and of raising awareness among the population at risk and among health personnel.

Key words: Breast cancer, Delay, Prognosis, Tumour biology 


\section{Introduction}

Breast cancer is the most frequently diagnosed malignant tumour in developed countries. In 2018, its incidence in Europe was 74.4 per 100,000 inhabitants and in Spain it was 74.5 per 100,000. In both geographic areas, breast cancer is the most prevalent form of cancer among women. However, its mortality Europe-wide is 14.9 per 100,000 but in Spain, only 10.6 per 100,000 . This difference influences the fiveyear prevalence, which is 534.7 per 100,000 inhabitants in Europe and 549.6 in Spain. Thanks to significant advances in diagnosis and treatment, mortality figures are low, compared to other tumours, but in consequence, the prevalence is very high (1), which heightens the need for healthcare resources for these patients; for example, the follow-up period is longer, and they require more specialised and individualised care (2).

This pathology is addressed by a wide variety of healthcare professionals, in both primary and hospital care, and so effective coordination is needed to ensure continuity and consistency. This coordination, in turn requires effective management of the processes involved in disease treatment (3)

Many factors must be taken into account in providing healthcare for a patient with breast cancer. Sociodemographic parameters, clinical characteristics and lifestyle habits can all influence the patient's situation and treatment needs. Moreover, comorbidities such as chronic obstructive pulmonary disease, chronic heart failure and diabetes produce a negative impact on the healthcare status of these patients $(4,5)$. Other variables that can influence the care process are age, sex and belief systems (6).

The diagnosis and/or treatment of breast cancer is sometimes delayed. Apart from clinical considerations, either type of delay can be psychologically distressing for patients (7). In the present study, we focus on surgical treatment delay (STD), taking as reference variables the dates of the biopsy and surgery performed. Opinions are divided as to whether STD is associated with shorter survival for breast cancer patients, as other clinical and sociodemographic factors are also involved, such as tumour stage, previous comorbidities and the patient's age (8-11). To enhance our understanding of these questions, this study evaluates the sociodemographic, clinical and pathological factors associated with STD in localised breast cancer, in a prospective cohort of patients. 


\section{Materials and methods}

\subsection{Study design}

Observational prospective multicentre study, with the participation of ten hospitals belonging to the Spanish National Health System, located in four Autonomous Communities (regions). The study population forms part of the NHS Breast Cancer and Health Services Research Cohort (CAMISS), belonging to the National Health System.

\subsection{Inclusion and exclusion criteria}

The prospective cohort was composed of 1236 patients, who were diagnosed through a screening programme or who presented symptoms during the period April 2013 to May 2015.

The patients included were all women aged at least 18 years, diagnosed with ductal carcinoma in situ, invasive ductal carcinoma, tubular carcinoma, mucinous carcinoma, papillary carcinoma, cribriform carcinoma o invasive lobular carcinoma.

Patients receiving neoadjuvant treatment, or who had been diagnosed with sarcoma, lymphoma or inflammatory carcinoma, or who suffered a recurrence of breast cancer, or whose disease was terminal or who presented any condition that interfered with their ability to complete the questionnaires were excluded.

\subsection{Study variables}

Data for the following study variables were compiled: the patient's personal history (age, educational background, employment status, household situation), health care, tumour history prior to the intervention, the surgery performed, pathological anatomy, hospital admission and follow-up. The EQ-5D health-related quality of life (HRQoL) instrument was applied. In this descriptive system, HRQoL is defined in terms of mobility, self-care, usual activities, pain/discomfort and anxiety/depression (12). STD was defined as the elapse of more than 30 days between the date of biopsy and the date of surgery.

\subsection{Ethical considerations}

Qualified research personnel informed patients of the nature and characteristics of this study, and all gave their signed consent before being included. All the study data were processed in accordance with applicable legislation, and the patient's confidentiality was protected at all times. The Ethics Committee at each 
participating hospital approved the study. This study is registered with Clinical Trials.gov (Identifier: NCT02439554).

\subsection{Statistical analysis}

In the descriptive analysis performed, measures of central tendency, position and dispersion were used for the quantitative variables, and of frequency distribution for the qualitative ones. Taking STD as the segmentation variable ( $\leq 30$ days vs. $>30$ days), bivariate analysis was performed using the chi-square test for dichotomous qualitative variables (or the linear test, for ordinal qualitative variables), and Student's t test for independent quantitative variables. The level of statistical significance assumed was $\mathrm{p}<0.05$.

In the multivariate analysis, the outcome variable taken was the presence of STD, and variables were considered by conditional forward and backward stepwise selection. The variables initially included in this analysis were all the independent variables for which $\mathrm{p}<0.01$ according to the bivariate analysis, in addition to the patient's age.

\section{Results}

The initial study population was composed of 1463 women with breast cancer, of whom 1270 had not received neoadjuvant treatment. After applying the inclusion and exclusion criteria, the final sample contained 1236 patients, of whom 689 experienced STD. The mean age of these patients, both overall and in the STD group, was 57.7 years (SD: 11.7\%) ( $\mathrm{p}=0.323)$ (Table 1). The median surgical delay was 35 and the IQR was 24. The mean BMI for all patients was 26.8 (SD: 5.5\%). For those in the non-STD group it was 26.4 (SD: 5.3\%) and for the STD group it was 27.2 (SD: 5.6\%). The difference was statistically significant $(\mathrm{p}=0.018)$

With respect to the patients' education background, the association with STD was inverse; in other words, patients with a higher level of education were less likely to suffer STD. Specifically, $63.3 \%$ of patients with no educational qualifications experienced STD, versus $50.4 \%$ of those with university studies $(\mathrm{p}<0.001)$.

Differences were also observed with respect to marital status. STD was most likely to affect widowed women $(66.2 \%)$, while only $46.6 \%$ of those were who single experienced delay $(\mathrm{p}=0.016)$. 
Of the patients who did not require assistance in the home, 376/614 (61.2\%) had experienced STD, whereas among those who did require such assistance, $285 / 540(52.82 \%)$ had been in this situation. The difference was statistically significant $(\mathrm{p}=0.005)$.

The responses to the EQ-5D HRQoL questionnaire (regarding mobility, self-care, usual activities, pain/discomfort and anxiety/depression) revealed significant differences in the presence or otherwise of anxiety-depression. Thus, $61 \%$ of the patients who presented this condition had experienced STD versus $51.3 \%$ of those with no such problem $(\mathrm{p}=0.002)$.

The Charlson index showed that STD was much more likely among patients who presented three or more comorbidities, among whom $65 \%$ experienced STD ( $\mathrm{p}=0.011)$. Similarly, symptomatic patients were more subject to STD than those who presented without symptoms $(\mathrm{p}=0.029)$ (Table 2).

Women with more advanced tumour stages were more likely to suffer STD $(\mathrm{p}=0.009)$. The delay was longer among patients who had a diagnosis other than infiltrating ductal carcinoma $(\mathrm{p}<0.001)$ and those with poorly-differentiated tumours $(\mathrm{p}=0.025)$. Finally, patients who had not undergone NMR spectroscopy were also more likely to experience STD $(\mathrm{p}<0.001)$

In the multivariate logistic regression model, among the sociodemographic variables, the presence of STD was independently predicted by educational background (maximum STD among those with "Primary education or less", OR: 1.54; 95\% CI: 1.13-2, 08), by BMI (OR: 1.04; 95\% CI: 1.01-1.07) and by those who needed assistance in the home (maximum STD among those classed as "Not needed", OR: 1.41; 95\% CI: $1.05-1.90)$. The relevant clinical variables were the presence of symptoms (OR: 1.69; $95 \%$ CI: 1.25 2.29) and the non-diagnosis of infiltrating ductal carcinoma (OR: 1.90; 95\% CI: 1, 37-2.63). The model achieved an acceptable goodness of fit, with a value of $\mathrm{p}=0.393$ according to the Hosmer and Lemeshow test (Table 3).

\section{Discussion}

Treatment delay for patients with breast cancer impacts on health and, probably, on survival (13), and therefore it is of vital importance to understand the factors involved. Moreover, it is important to address the questions of fairness that must be taken into account in the scheduling and administration of treatments. Waiting for treatment is one of the events that produces most stress among patients and delay is one of their most frequent causes of complaint (14). Unlike previous research in this field, the present study 
prospectively evaluates a large number of patients diagnosed and treated in different public-sector hospitals (15). Over half of our study sample experienced STD. The impact was most severe among patients with little or no formal education, those who did not require home assistance, those with a high BMI and those whose condition was symptomatic.

In fact, more than half of all patients affected by STD had few educational qualifications. This parameter has been cited in previous studies of treatment delay, for other types of tumours (16). Our work, thus, corroborates previous research, underlining the conclusion that the empowerment of patients is a factor that directly affects the healthcare decisions taken. In short, education background is a powerful factor underlying the patient's involvement in potentially crucial treatment decisions (17-20).

Our study results also show that marital status and the need for assistance in the home are significantly related to the psychosocial support received, which is known to reinforce adherence to treatment and follow-up $(21,22)$. In our study sample, a large proportion of the women who experienced STD were widows, whose isolation at least in part accounts for the greater likelihood of their being affected by treatment delay. A similar reasoning is applicable to the case of patients who do not need assistance in the home. These findings corroborate our hypothesis of a close relationship between STD and the absence of psychosocial support. Patients with greater assistance needs due to a loss of autonomy require continuous care at the social and health levels, which may mean they receive greater attention in disease treatment, due to their more frequent contact with the health system.

An important aspect of the present study is that it is based on the use of a validated measurement instrument, the EQ-5D HRQoL questionnaire, which objectively evaluates patients' experience of healthcare diagnosis and treatment in cases of breast cancer (12). With respect to the quality of life, more than half of the patients who experienced STD presented anxiety and/or depression (23), possibly due to their concerns and lack of optimism about the surgery proposed and the course of their disease $(24,25)$.

High BMI, overweight and obesity are known risk factors for breast cancer (26). Furthermore, although research findings in this respect are scarce, obesity is considered a risk factor for any type of intervention, which might justify delaying surgery. Moreover, obese patients are at greater risk of suffering treatment complications, compared to those with normal BMI $(27,28)$. In this respect, Roy et al. (2019) proposed a risk stratification model for immediate microvascular breast reconstruction in which obesity was 
incorporated as an important predictor (29). For these reasons, a high BMI may increase the waiting time for surgery, an association that is confirmed in our study.

The Charlson index for our study results shows there is a positive association between STD and the presence of comorbidities, which confirms a study conducted in the USA by Yancik et al. (2001), who reported that the greater the number of comorbidities, the lower the patient's probability of receiving the recommended treatment (30). This association may be due to the physician having to evaluate various treatment options for patients with multimorbidity, or because they are not candidates for more extensive primary treatment or because they might not be able to withstand it. Any of these considerations might cause a delay in reaching a final surgical decision $(31,32)$.

Treatment delay for symptomatic patients may be motivated by the aggressiveness of the tumours, as suggested by the association observed in our patients between STD and tumour stage and degree of differentiation. In advanced stages of the disease, diagnosis may lead to more complementary tests being conducted, requiring more time before surgery can be performed. However, in a study of patients with breast cancer, Redondo et al. (2009) observed a shorter treatment delay in patients whose disease was at a more advanced stage (13). This conflicting finding might be indicative of the changing nature of treatment for breast cancer, from a period when fewer complementary tests were performed after mammography, such as biopsy and the labelling of suspicious nodules. Furthermore, multidisciplinary committees are now commonly formed to carry out a more comprehensive assessment of the patient's condition, sometimes requiring further diagnostic tests and even second biopsies (3).

Infiltrating ductal carcinoma is one of the most common diagnoses in breast cancer, and is also one of the most common histological types found in advanced stages of the disease (33). As this tumour is highly aggressive, it should come as no surprise that it is associated with lower levels of treatment delay compared with other histological types, as has also been reported in previous studies (13). When a histological type such as lobular carcinoma is identified, it is recommended that the study be extended with a mammary MRI since these tumours are usually multifocal and/or multicentric. In this diagnostic test, suspicious lesions may appear, requiring further biopsies and diagnostic confirmation, thus delaying the first treatment. Furthermore, since the tumours are frequently multicentric, a mastectomy is usually required. This factor, too, could result in treatment being delayed (34). Finally, in this large group of non-IDC tumours there would also be carcinomas in situ, which due to their low risk to life are often treated non- preferentially. 
The present study has certain limitations, which should be acknowledged. Ideally, we should have assessed the first treatment received, whether surgery, chemotherapy, radiotherapy or any other approach. However, patients with neoadjuvant treatment had to be excluded from the study sample because in many cases the date of first treatment was unknown. For this reason, we define STD as the period elapsed from biopsy until the surgical intervention, i.e. the first treatment for women who did not receive neoadjuvant treatment. Another consideration is that little previous research has been conducted in this field, which hampers our ability to compare and corroborate our findings, although it also represents a plus point in that the data reported are novel. Furthermore, as a strength of this study, the period of treatment delay considered is comparable to that assumed in earlier papers $(11,35,36)$. Finally, the multicentre nature of our research enhances the representativeness of the data analysed.

In view of the findings obtained in this research, the implementation of measures to reduce the surgical waiting times for patients with breast cancer is recommended.

To conclude, we emphasise that certain risk habits and sociodemographic and clinical variables have a negative impact on STD. Our identification of factors that influence surgical delay highlights the need to raise awareness of their importance among the population at risk and among healthcare personnel. In addition, more attention should be paid to patients with little formal education, in order to enhance the clinical management of their cancer.

\section{Conflicts of interest}

The authors declare that they have no conflict of interest regarding the present study.

\section{Funding}

This study was funded by the Carlos III Health Institute through projects "PI12/01842, PI12/02493" and by the Andalusian Ministry of Health through project "16/298” (co-funded by the European Social Fund / European Regional Development Fund "Investing in your future").

These institutions played no role in the study design, in the collection, analysis and interpretation of data, in the writing of the manuscript or in the decision to submit the document for publication.

\section{Bibliography}

1. GCO. Global Cancer Observatory [Internet]. Vol. 593, International Agency for Research of 
Cancer. 2019 [citado 27 de enero de 2020]. p. 1-2. Disponible en: https://gco.iarc.fr/

2. Puigpinós-Riera R, Castillo Gómez A, Romero Morales A, Aller M, Castells X, Sala M. Social and clinical determinants of the use of health services in women with breast cancer (Cohort DAMA). Gaceta Sanitaria. 1 de septiembre de 2019;33(5):434-41.

3. Clinical Practice Guidelines on Breast Cancer [Internet]. [citado 30 de marzo de 2020]. Disponible en: https://www.esmo.org/guidelines/breast-cancer

4. Griffiths RI, Gleeson ML, Valderas JM, Danese MD. Impact of undetected comorbidity on treatment and outcomes of breast cancer. International journal of breast cancer. 2014;2014:970780.

5. Kiderlen M, de Glas NA, Bastiaannet E, van de Water W, de Craen AJM, Guicherit OR, et al. Impact of comorbidity on outcome of older breast cancer patients: a FOCUS cohort study. Breast Cancer Research and Treatment [Internet]. 2014;145(1):185-92. Disponible en: https://doi.org/10.1007/s10549-014-2917-7

6. Gu J, Groot G, Boden C, Busch A, Holtslander L, Lim H. Review of Factors Influencing Women's Choice of Mastectomy Versus Breast Conserving Therapy in Early Stage Breast Cancer: A Systematic Review. Vol. 18, Clinical Breast Cancer. Elsevier Inc.; 2018. p. e539-54.

7. Barton MB, Morley DS, Moore S, Allen JD, Kleinman KP, Emmons KM, et al. Decreasing women's anxieties after abnormal mammograms: A controlled trial. Journal of the National Cancer Institute. 7 de abril de 2004;96(7):529-38.

8. Richards MA, Westcombe AM, Love SB, Littlejohns P, Ramirez AJ. Influence of delay on survival in patients with breast cancer: a systematic review. Lancet (London, England), abril de 1999;353(9159):1119-26.

9. Brazda A, Estroff J, Euhus D, Leitch AM, Huth J, Andrews V, et al. Delays in Time to Treatment and Survival Impact in Breast Cancer. Annals of Surgical Oncology [Internet]. 2010;17(3):291-6. Disponible en: https://doi.org/10.1245/s10434-010-1250-6

10. Bleicher RJ. Timing and Delays in Breast Cancer Evaluation and Treatment. Annals of Surgical Oncology [Internet]. 2018;25(10):2829-38. Disponible en: https://doi.org/10.1245/s10434-018$6615-2$ 
11. Baena-Canada JM, Rodriguez-Perez L, Gamez-Casado S, Quilez-Cutillas A, Cortes-Carmona C, Rosado-Varela P, et al. Evaluation of waiting times for breast cancer diagnosis and surgical treatment. Clinical \& translational oncology : official publication of the Federation of Spanish Oncology Societies and of the National Cancer Institute of Mexico. octubre de 2018;20(10):134552.

12. Brooks R, De Charro F. EuroQol: The current state of play. Health Policy. 1996;37(1):53-72.

13. Redondo M, Rodrigo I, Pereda T, Funez R, Acebal M, Perea-Milla E, et al. Prognostic implications of emergency admission and delays in patients with breast cancer. Supportive care in cancer: official journal of the Multinational Association of Supportive Care in Cancer. mayo de 2009;17(5):595-9.

14. Singh J, Edge SB, Bonaccio E, Schwert KT, Braun B. Breast cancer center: improving access to patient care. Journal of the National Comprehensive Cancer Network : JNCCN. February 2014;12 Suppl 1:S28-32.

15. García-Gutierrez S, Orive M, Sarasqueta C, Legarreta MJ, Gonzalez N, Redondo M, et al. Health services research in patients with breast cancer (CAMISS-prospective): study protocol for an observational prospective study. BMC Cancer [Internet]. 2018;18(1):54. Disponible en: https://doi.org/10.1186/s12885-017-3926-9

16. Zarcos-Pedrinaci I, Fernández-López A, Téllez T, Rivas-Ruiz F, Rueda A, Morales Suarez-Varela MM, et al. Factors that influence treatment delay in patients with colorectal cancer. Oncotarget. mayo de 2017;8(22):36728-42.

17. Barlow C, Cooke D, Mulligan K, Beck E, Newman S. A critical review of self-management and educational interventions in inflammatory bowel disease. Gastroenterology nursing : the official journal of the Society of Gastroenterology Nurses and Associates. 2010;33(1):11-8.

18. Klikovac T, Djurdjevic A. Psychological aspects of the cancer patients' education: thoughts, feelings, behavior and body reactions of patients faced with diagnosis of cancer. Journal of BUON : official journal of the Balkan Union of Oncology. 2010;15(1):153-6.

19. Partin MR, Nelson D, Radosevich D, Nugent S, Flood AB, Dillon N, et al. Randomized trial examining the effect of two prostate cancer screening educational interventions on patient 
knowledge, preferences, and behaviors. Journal of general internal medicine. agosto de 2004;19(8):835-42.

20. Sulakvelidze N, Burdick B, Kaklamani V, Tilton K, Baker K, Kim J, et al. Evaluating the Effect of a Video Education Curriculum for First Time Breast Cancer Patients: a Prospective RCT Feasibility Study. Journal of cancer education : the official journal of the American Association for Cancer Education. diciembre de 2019;34(6):1234-40.

21. Forsythe LP, Alfano CM, Kent EE, Weaver KE, Bellizzi K, Arora N, et al. Social support, selfefficacy for decision-making, and follow-up care use in long-term cancer survivors. Psychooncology. julio de 2014;23(7):788-96.

22. Arora NK, Finney Rutten LJ, Gustafson DH, Moser R, Hawkins RP. Perceived helpfulness and impact of social support provided by family, friends, and health care providers to women newly diagnosed with breast cancer. Psycho-oncology. mayo de 2007;16(5):474-86.

23. Herdman M, Gudex C, Lloyd A, Janssen MF, Kind P, Parkin D, et al. Development and preliminary testing of the new five-level version of EQ-5D (EQ-5D-5L). Quality of Life Research [Internet]. 2011;20(10):1727-36. Disponible en: https://doi.org/10.1007/s11136-011-9903-x

24. Epping-Jordan JE, Compas BE, Osowiecki DM, Oppedisano G, Gerhardt C, Primo K, et al. Psychological adjustment in breast cancer: Processes of emotional distress. Vol. 18, Health Psychology. US: American Psychological Association; 1999. p. 315-26.

25. Gibbons A, Groarke A, Sweeney K. Predicting general and cancer-related distress in women with newly diagnosed breast cancer. BMC cancer. diciembre de 2016;16(1):935.

26. Engin A. Obesity-associated Breast Cancer: Analysis of risk factors. Advances in experimental medicine and biology. 2017;960:571-606.

27. Jomphe V, Mailhot G, Damphousse V, Tahir M-R, Receveur O, Poirier C, et al. The Impact of Waiting List BMI Changes on the Short-term Outcomes of Lung Transplantation. Transplantation. febrero de 2018;102(2):318-25.

28. Piotti G, Gandolfini I, Palmisano A, Maggiore U. Metabolic risk profile in kidney transplant candidates and recipients. Nephrology, dialysis, transplantation: official publication of the 
European Dialysis and Transplant Association - European Renal Association. marzo de 2019;34(3):388-400.

29. Roy M, Sebastiampillai S, Haykal S, Zhong T, Hofer SOP, O’Neill AC. Development and validation of a risk stratification model for immediate microvascular breast reconstruction. Journal of surgical oncology. diciembre de 2019;120(7):1177-83.

30. Yancik R, Wesley MN, Ries LAG, Havlik RJ, Edwards BK, Yates JW. Effect of Age and Comorbidity in Postmenopausal Breast Cancer Patients Aged 55 Years and Older. JAMA [Internet]. 21 de febrero de 2001;285(7):885-92. Disponible en: https://doi.org/10.1001/jama.285.7.885

31. Louwman WJ, Janssen-Heijnen MLG, Houterman S, Voogd AC, van der Sangen MJC, Nieuwenhuijzen GAP, et al. Less extensive treatment and inferior prognosis for breast cancer patient with comorbidity: a population-based study. European journal of cancer (Oxford, England : 1990). marzo de 2005;41(5):779-85.

32. Berglund A, Wigertz A, Adolfsson J, Ahlgren J, Fornander T, Wärnberg F, et al. Impact of comorbidity on management and mortality in women diagnosed with breast cancer. Breast Cancer Research and Treatment [Internet]. 2012;135(1):281-9. Disponible en: https://doi.org/10.1007/s10549-012-2176-4

33. Li CI, Uribe DJ, Daling JR. Clinical characteristics of different histologic types of breast cancer. British Journal of Cancer [Internet]. 2005;93(9):1046-52. Disponible en: https://doi.org/10.1038/sj.bjc.6602787

34. Hulvat M, Sandalow N, Rademaker A, Helenowski I, Hansen NM. Time from diagnosis to definitive operative treatment of operable breast cancer in the era of multimodal imaging. Surgery. October 2010;148(4):741-6.

35. Comber H, Cronin DP, Deady S, Lorcain PO, Riordan P. Delays in treatment in the cancer services: impact on cancer stage and survival. Irish medical journal. septiembre de 2005;98(8):238-9.

36. Molinie F, Leux C, Delafosse P, Ayrault-Piault S, Arveux P, Woronoff AS, et al. Waiting time disparities in breast cancer diagnosis and treatment: a population-based study in France. Breast (Edinburgh, Scotland). octubre de 2013;22(5):810-6. 


\begin{tabular}{|c|c|c|c|c|c|c|c|c|}
\hline \multirow{3}{*}{\multicolumn{2}{|c|}{ Variable }} & \multirow{2}{*}{\multicolumn{2}{|c|}{ Total (n: 1236) }} & \multicolumn{4}{|c|}{ Surgical treatment delay } & \multirow{3}{*}{$\mathbf{p}$} \\
\hline & & & & \multicolumn{2}{|c|}{$\leq 30$ days (n: 547) } & \multicolumn{2}{|c|}{ >30 days (n: 689) } & \\
\hline & & Mean & SD & Mean & SD & Mean & SD & \\
\hline $\operatorname{Age}^{(1)}$ & & 57.7 & 11.7 & 57.4 & 11.2 & 58.1 & 12.1 & 0.323 \\
\hline \multirow{4}{*}{\multicolumn{2}{|c|}{ BMI (2) }} & 26.8 & 5.5 & 26.4 & 5.3 & 27.2 & 5.6 & 0.018 \\
\hline & & \multirow{2}{*}{\multicolumn{2}{|c|}{ Total (n: 1236) }} & \multicolumn{4}{|c|}{ Surgical treatment delay } & $\mathbf{p}$ \\
\hline & & & & \multicolumn{2}{|c|}{$\leq 30$ days $(n: 547)$} & \multicolumn{2}{|c|}{ >30 days (n: 689) } & $\mathbf{p}$ \\
\hline & & $\mathbf{N}$ & $\%$ & $\mathbf{n}$ & $\%$ & $\mathbf{n}$ & $\%$ & \\
\hline \multicolumn{9}{|c|}{ Education background ${ }^{(3)}$} \\
\hline & No formal education & 150 & 13.1 & 55 & 36.7 & 95 & 63.3 & $<0.001$ \\
\hline & Primary education & 463 & 40.5 & 179 & 38.7 & 284 & 61.3 & $<0.001$ \\
\hline & Secondary education & 269 & 23.5 & 121 & 45.0 & 148 & 55.0 & \\
\hline & University education & 262 & 22.9 & 130 & 49.6 & 132 & 50.4 & \\
\hline \multicolumn{9}{|c|}{ Occupationally active ${ }^{(4)}$} \\
\hline & No & 615 & 53.8 & 251 & 40.8 & 364 & 59.2 & \multirow{2}{*}{0.194} \\
\hline & Yes & 529 & 46.2 & 237 & 44.8 & 292 & 55.2 & \\
\hline \multicolumn{9}{|c|}{ Marital status ${ }^{(5)}$} \\
\hline & Single & 118 & 10.2 & 63 & 53.4 & 55 & 46.6 & \multirow{4}{*}{0.016} \\
\hline & Married/Cohabiting & 768 & 66.6 & 326 & 42.4 & 442 & 57.6 & \\
\hline & Separated-Divorced & 122 & 10.6 & 54 & 44.3 & 68 & 55.7 & \\
\hline & Widowed & 145 & 12.6 & 49 & 33.8 & 96 & 66.2 & \\
\hline \multicolumn{9}{|c|}{ Need home assistance ${ }^{(6)}$} \\
\hline & No & 614 & 53.2 & 238 & 38.8 & 376 & 61.2 & \multirow{2}{*}{0.005} \\
\hline & Yes & 540 & 46.8 & 255 & 47.2 & 285 & 52.8 & \\
\hline \multicolumn{9}{|c|}{ Receive social assistance ${ }^{(7)}$} \\
\hline & No & 997 & 86.8 & 426 & 42.7 & 571 & 57.3 & \multirow{2}{*}{0.942} \\
\hline & Yes & 152 & 13.2 & 66 & 43.4 & 86 & 56.6 & \\
\hline \multicolumn{9}{|c|}{ Household situation ${ }^{(8)}$} \\
\hline & Living alone & 182 & 15.8 & 72 & 39.6 & 110 & 60.4 & 0.403 \\
\hline & Accompanied & 967 & 84.2 & 418 & 43.2 & 549 & 56.8 & 0.403 \\
\hline Pregnant & & & & & & & & \\
\hline & No & 958 & 98.4 & 396 & 41.3 & 562 & 58.7 & 0.958 \\
\hline & Yes & 16 & 1.6 & 6 & 37.5 & 10 & 62.5 & \\
\hline Baseline $\mathbf{E}$ & & & & & & & & \\
\hline & No problems & 1020 & 87.9 & 439 & 43 & 581 & 57 & 0.511 \\
\hline & Problems & 141 & 12.1 & 56 & 39.7 & 85 & 60.3 & 0.511 \\
\hline Baseline $\mathbf{E}$ & (11) & & & & & & & \\
\hline & No problems & 1100 & 94.9 & 466 & 42.4 & 634 & 57.6 & 0704 \\
\hline & Problems & 59 & 5.1 & 27 & 45.8 & 32 & 54.2 & \\
\hline Baseline $\mathbf{E}$ & ivities ${ }^{(12)}$ & & & & & & & \\
\hline & No problems & 1012 & 87.2 & 428 & 42.3 & 584 & 57.7 & 0.552 \\
\hline & Problems & 148 & 12.8 & 67 & 45.3 & 81 & 54.7 & \\
\hline Baseline $\mathbf{E}$ & omfort ${ }^{(13)}$ & & & & & & & \\
\hline & No problems & 738 & 63.6 & 328 & 44.4 & 410 & 55.6 & 0.113 \\
\hline & Problems & 423 & 36.4 & 167 & 39.5 & 256 & 60.5 & 0.115 \\
\hline Baseline $\mathbf{E}$ & Depression ${ }^{(14)}$ & & & & & & & \\
\hline & No problems & 421 & 36.3 & 205 & 48.7 & 216 & 51.3 & 0.002 \\
\hline & Problems & 738 & 63.7 & 288 & 39 & 450 & 61 & \\
\hline
\end{tabular}

Note: The percentage for total patients is expressed by the column, and percentage by treatment delay, by the row.

Losses: $1=4 ; 2=319 ; 3=92 ; 4=92 ; 5=83 ; 6=82 ; 7=87 ; 8=87 ; 9=262 ; 10=75 ; 11=77 ; 12=76 ; 13=75 ; 14=77$

BMI: Body Mass Index/ EQ-5D: European Quality of Life- 5 dimensions/ SD: Standard deviation

Table 1. Outcomes according to sociodemographic and HRQoL variables 


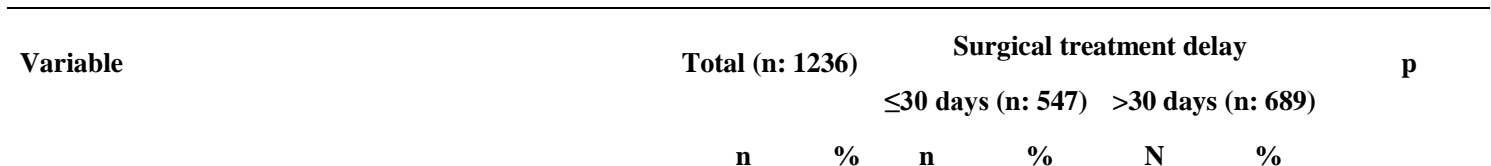

Habitual smoker $^{(1)}(\mathrm{n}-\%)$

n $\quad$ n

$\% \quad \mathrm{~N} \quad \%$

$\begin{array}{rccccc}\text { Never } & 659 & 267 & 40.5 & 392 & 59.5 \\ \text { Current } & 267 & 126 & 47.2 & 141 & 52.8 \\ \text { Ex-smoker } & 190 & 87 & 45.8 & 103 & 54.2\end{array}$

Habitual alcohol use ${ }^{(2)}(\mathrm{n}-\%)$

$\begin{array}{rrrrcrr}\text { No } & 1210 & 533 & 44.0 & 677 & 56.0 & 0.519 \\ \text { Yes } & 9 & 5 & 55.6 & 4 & 44.4 & \end{array}$

Prior neoplasia (n - \%)

$\begin{array}{rrrrrrr}\text { No } & 1122 & 498 & 44.4 & 624 & 55.6 & 0.851 \\ \text { Yes } & 114 & 49 & 43.0 & 65 & 57.0 & \end{array}$

Family history of gynaecologic cancer ${ }^{(3)}(\mathrm{n}-\%)$

$\begin{array}{lllllll}\text { No } & 769 & 331 & 43.0 & 438 & 57.0 & 0.919 \\ \text { Yes } & 425 & 185 & 43.5 & 240 & 56.5 & \end{array}$

Charlson index $(\mathrm{n}-\%)$

$\operatorname{Asymptomatic~}^{(4)}(\mathrm{n}-\%)$

$\begin{array}{rrrrrrr}0 & 968 & 449 & 46.4 & 519 & 53.6 & \\ 1 & 160 & 58 & 36.3 & 102 & 63.8 & \mathbf{0 . 0 1 1} \\ 2 & 76 & 29 & 38.2 & 47 & 61.8 & \\ 3 \text { or more } & 32 & 11 & 34.4 & 21 & 65.6 & \end{array}$

Detected by screening (n - \%)

$\begin{array}{lllllll}\text { No } & 521 & 211 & 40.5 & 310 & 59.5 & \mathbf{0 . 0 2 9} \\ \text { Yes } & 714 & 335 & 46.9 & 379 & 53.1 & \end{array}$

\begin{tabular}{|c|c|c|c|c|c|c|c|}
\hline & No & 551 & 227 & 41.2 & 324 & 58.8 & \multirow{2}{*}{0.06} \\
\hline & Yes & 685 & 320 & 46.7 & 365 & 53.3 & \\
\hline \multicolumn{8}{|l|}{ Tumour stage $^{(5)}(\mathrm{n}-\%)$} \\
\hline & 0 & 126 & 50 & 39.7 & 76 & 60.3 & \multirow{4}{*}{0.009} \\
\hline & I & 663 & 319 & 48.1 & 344 & 51.9 & \\
\hline & II & 341 & 141 & 41.3 & 200 & 58.7 & \\
\hline & III-IV & 82 & 26 & 31.7 & 56 & 68.3 & \\
\hline \multicolumn{8}{|l|}{ Infiltrating ductal carcinoma $^{(6)}(\mathrm{n}-\%)$} \\
\hline & No & 469 & 175 & 37.3 & 294 & 62.7 & \multirow{2}{*}{$<0.001$} \\
\hline & Yes & 763 & 372 & 48.8 & 391 & 51.2 & \\
\hline \multicolumn{8}{|l|}{ Degree of differentiation $^{(7)}(n-\%)$} \\
\hline & I & 273 & 139 & 50.9 & 134 & 49.1 & \multirow{3}{*}{0.025} \\
\hline & II & 597 & 260 & 43.6 & 337 & 56.4 & \\
\hline & III & 278 & 115 & 41.4 & 163 & 58.6 & \\
\hline \multicolumn{8}{|l|}{ Expression of $\mathbf{E R}^{(\boldsymbol{8})}(\mathrm{n}-\%)$} \\
\hline & Negative & 147 & 68 & 46.3 & 79 & 53.7 & \multirow[t]{2}{*}{0.721} \\
\hline & Positive & 1063 & 471 & 44.3 & 592 & 55.7 & \\
\hline \multicolumn{8}{|l|}{ Expression of $\mathbf{P R}^{(09)}(\mathrm{n}-\%)$} \\
\hline & Negative & 272 & 126 & 46.3 & 146 & 53.7 & \multirow{2}{*}{0.557} \\
\hline & Positive & 937 & 413 & 44.1 & 524 & 55.9 & \\
\hline
\end{tabular}

Expression of HER2 ${ }^{(10)}(\mathrm{n}-\%)$ 


$\begin{array}{rrrrrrr}\text { Negative } & 1039 & 472 & 45.4 & 567 & 54.6 & 0.319 \\ \text { Positive } & 110 & 56 & 50.9 & 54 & 49.1 & \end{array}$

$\operatorname{MNR}^{(11)}(\mathrm{n}-\%)$

\begin{tabular}{rllllll} 
No & 476 & 171 & 35.9 & 305 & 64.1 & $<\mathbf{0 . 0 0 1}$ \\
Yes & 758 & 375 & 49.5 & 383 & 50.5 & \\
\hline
\end{tabular}

Note: The percentage for total patients is expressed by the column, and percentage by treatment delay, by the row.

Losses: $1=120 ; 2=17 ; 3=42 ; 4=1 ; 5=24 ; 6=2 ; 7=4 ; 8=26 ; 9=27 ; 10=87 ; 11=88$

ER: Estrogen Receptor /PR: Progesterone Receptor/HER2: Human Epidermal Growth Factor Type II /MNR: Magentic Nuclear Resonance

Table 2. Outcomes according to risk habits and clinical variables 


\begin{tabular}{|c|c|c|c|c|c|c|}
\hline \multirow{2}{*}{\multicolumn{2}{|c|}{ Variable }} & \multirow{2}{*}{$\boldsymbol{\beta}$} & \multirow{2}{*}{$\mathbf{p}$} & \multirow{2}{*}{ Odds ratio } & \multicolumn{2}{|c|}{$95 \% \mathrm{CI}$} \\
\hline & & & & & Lower & Upper \\
\hline \multicolumn{7}{|c|}{ Education } \\
\hline & Secondary-University & & & 1.00 & & \\
\hline & None-Primary & 0.43 & 0.01 & 1.54 & 1.13 & 2.08 \\
\hline BMI & & 0.04 & 0.01 & 1.04 & 1.01 & 1.07 \\
\hline \multicolumn{7}{|c|}{ Need assistance } \\
\hline & Yes & & & 1.00 & & \\
\hline & No & 0.34 & 0.02 & 1.41 & 1.05 & 1.90 \\
\hline \multicolumn{7}{|c|}{ Asymptomatic } \\
\hline & Yes & & & 1.00 & & \\
\hline & No & 0.53 & $<0.001$ & 1.69 & 1.25 & 2.29 \\
\hline \multicolumn{7}{|c|}{ Histologies other than IDC } \\
\hline & Yes & 0.64 & $<0.001$ & 1.90 & 1.37 & 2.63 \\
\hline & No & & & 1.00 & & \\
\hline
\end{tabular}

Table 3. Multivariate logistic regression model for presence of surgical treatment delay (>30 days) 